\title{
Treatment of psychopathic offenders: Evidence, issues, and controversies
}

\author{
Mark E. Olver*
}

\begin{abstract}
Psychopathic offenders are a notoriously challenging population to treat, who are often recalcitrant to change and at high risk for program non-completion and recidivism. The present work is a review and synthesis of the evidence, issues, and controversies in the treatment of psychopathic offenders. The operationalization and measurement of the construct of psychopathy via the Hare Psychopathy Checklist-Revised is reviewed to give context to the population being treated and to identify latent features of the syndrome that have risk and treatment implications. A discussion of the issues and challenges in the treatment of psychopathic offenders is then provided to contextualize the source of therapeutic pessimism with this population, followed by a review of the existing psychopathy treatment literature. The characteristics of unsuccessful and encouraging treatment programs, including a promising model of treatment, are subsequently reviewed, and the article finishes with a synopsis of recent treatment outcome findings published subsequent to previous psychopathy treatment reviews or inadvertently overlooked by past reviews. Although psychopathic offenders are a challenging population to treat, I argue that they are not immune to making positive lifestyle and behavioural changes, and that these individuals have the potential to benefit if they can be retained in treatment.
\end{abstract}

Key Words Psychopathy; Psychopathy Checklist-Revised; treatment; recidivism; change.

Journal of CSWB. 2016 Nov; 1(3):75-82

www.journalcswb.ca

\section{INTRODUCTION}

Psychopathy is a serious personality disorder with destructive social consequences. Interpersonally, psychopaths are superficial, grandiose, deceitful and manipulative. Affectively, psychopaths are callous, lack empathy or guilt, have a shallow range of emotion and fail to accept responsibility for wrongdoing. And behaviourally, psychopaths live an impulsive irresponsible lifestyle, often living in the moment, failing to set down roots and parasitizing off of the good faith and charity of others. They demonstrate a persistent pattern of antisocial behaviour that tends to begin with behaviour problems early in life (e.g., stealing, truancy, lying, bullying), progressing into a pattern of diverse criminal activity throughout their teen years and into adulthood.

The present work is a review and synthesis of the evidence, issues, and controversies in the treatment of psychopathic offenders. I begin by reviewing the operationalization and measurement of the construct of psychopathy in order to give context to the population being treated, and to identify latent features of the syndrome that have risk and treatment

Part of a Continuing Series: Proceedings of the $16^{\text {th }}$ Biennial Violence and Aggression Symposium, University of Saskatchewan, June 2016. implications. I then discuss a range of issues and challenges in the treatment of psychopathic offenders to contextualize the source of therapeutic pessimism with this population, and follow with a review of the existing psychopathy treatment literature. I proceed to review the characteristics of both unsuccessful and encouraging treatment programs, including a more detailed discussion of a promising model of treatment, and close with a synopsis of recent outcome findings published subsequent to previous psychopathy treatment reviews, or inadvertently overlooked by such past reviews. Although psychopathic offenders are a challenging population to treat, I argue that they are not immune to making positive lifestyle and behavioural changes, and that these individuals have the potential to benefit if they can be retained in treatment.

\section{PSYCHOPATHY OPERATIONALLY DEFINED}

For the purposes of the present review, psychopathy is operationally defined by high scores on the Hare Psychopathy Checklist-Revised (PCL-R; Hare, 1991, 2003), a 20-item symptom construct rating scale designed to assess the core traits of psychopathy. Each item is scored on a 0 (absent), 1 (partially/possibly present), 2 (present) ordinal scale 
with possible scores ranging from 0 to 40 . The total score represents the extent to which the individual resembles the prototypical psychopath. Typically, a cut score of 30 is used to diagnose an individual as psychopathic, although high scores approaching this value (e.g., 28 or 29) are informative. The PCL-R items can be further divided into two broad factors: Factor 1 represents the interpersonal and affective features of the syndrome, or the psychopath's personality and emotional style, while Factor 2 represents the chronic antisocial lifestyle pattern of psychopathy. Factor 1 in turn can be subdivided into lower order factors termed Interpersonal (e.g., superficial charm, deceitfulness) and Affective (e.g., callous lack of empathy, absence of remorse), while Factor 2 can be subdivided into Lifestyle (e.g., irresponsibility, impulsivity, parasitic) and Antisocial (e.g., poor behavioural controls, juvenile delinquency, criminal versatility) factors (Hare \& Neumann, 2008; 2010). The PCL-R has several variants including a screening version (PCL: SV; Hart, Cox, \& Hare, 1995) and youth version (PCL: YV; Forth, Kosson, \& Hare, 2003).

High scores on the PCL-R or its variants have been shown to be strong predictors of violent and general criminal recidivism (Leistico, Salekin, DeCoster, \& Rogers, 2008), institutional misconducts (Guy, Edens, Anthony, \& Douglas, 2005), failure on conditional release (Hart, Kropp, \& Hare, 1988), lengthy criminal careers (Olver \& Wong, 2015), and sexual violence, particularly when psychopathy co-occurs with deviant sexual interests (Hawes, Boccaccini, \& Murrie, 2013). Psychopaths comprise roughly $15 \%$ to $25 \%$ of incarcerated populations yet only about $1 \%$ of the general public (Hare, 1996; Wong, 1984) - figures that have remained relatively stable, although this group tends to have greater representation among violent offender and sexual offender populations. Some high-intensity violence reduction treatment programs report base rates of psychopathy exceeding 50\% (Lewis, Olver, \& Wong, 2013), while approximately one-third of rapists, in contrast to approximately $5 \%-10 \%$ of child sexual abusers, would meet the PCL-R criteria for psychopathy (e.g., Beggs \& Grace, 2008; Olver \& Wong, 2006; Porter, Fairweather, Dugge, Hervé, Birt, \& Boer, 2000).

\section{ISSUES AND CHALLENGES IN THE TREATMENT OF PSYCHOPATHIC OFFENDERS}

Clearly not all offenders are psychopathic, and even the majority of men who commit sexual and violent offenses do not fit the symptom criteria of psychopathy. And not all psychopaths inevitably reoffend violently or otherwise. A longitudinal study of psychopathy and age found that even psychopaths had declining rates of various recidivism outcomes at older ages (Olver \& Wong, 2015). There is, however, much mystique, controversy, and therapeutic pessimism in the response of psychopathic offenders to intervention efforts (Salekin, 2002). In his seminal work more than 60 years ago, British psychiatrist Hervey Cleckley (1941) concluded “... we do not at present have any kind of psychotherapy that can be relied upon to change the psychopath fundamentally" (pp. 438-439). More than 30 years later, Suedfeld and Landon (1978) similarly offered, "Review of the literature suggests that a chapter on effective treatment should be the shortest in any book concerned with psychopathy. In fact, it has been suggested that one sentence would suffice: No demonstrably effective treatment has been found" (p. 347). And in the past decade, Harris and Rice (2006) have stated "...no effective interventions yet exist for psychopaths. Indeed, some treatments that are effective for non-psychopaths actually increase the risk of represented by psychopaths" (p. 563). Before delving further into the existing psychopathy treatment outcome literature to put such assertions to the test, I review some of the issues and challenges in working clinically with psychopathic offenders that partly fuel such pessimism.

First, psychopathic offenders are very challenging to treat, typically responding more poorly to treatment programs, lacking motivation, and showing greater resistance to change (Ogloff, Wong, \& Greenwood, 1990). A recent meta-analysis of offender treatment attrition programs found PCL-R score and psychopathy diagnosis to be among the strongest predictors of treatment non-completion, with a diagnosis of psychopathy being associated with a $30 \%$ increase in program dropout (Olver, Stockdale, \& Wormith, 2011). Moreover, an outcome study of 154 men attending the Clearwater High Intensity Sex Offender Treatment Program at the Regional Psychiatric Centre (RPC) in Saskatoon, SK, found that PCL-R Factor 1 in general, and the Affective facet in particular (i.e., the callous unemotional features of psychopathy), were particularly strong predictors of treatment failure (Olver \& Wong, 2011).

Second, psychopaths also form weaker therapeutic bonds. A follow-up investigation of psychopathy and working alliance conducted out of the Clearwater Program (DeSorcy, Olver, \& Wormith, 2016) found that PCL-R factor scores were inversely related to patient-therapist ratings on a paper-andpencil measure of the working alliance, the Working Alliance Inventory (WAI). In particular, the Affective facet was associated with lower Bond scores on the WAI; that is, prominent callous-unemotional features were associated with weaker emotional connections reported by the patient with their therapists. It has also been shown that psychopathic offenders showed poorer therapeutic work ethic, particularly men scoring high on the Lifestyle facet, which was associated with poorer performance of relevant therapeutic tasks in treatment sessions.

Third, psychopathic offenders do evidence less treatment progress or improvement than non-psychopaths. An investigation of 152 men who attended a high-intensity violence reduction program (the Aggressive Behavioural Control, or ABC, Program) at the RPC found that PCL-R score and each of the four factors were inversely related to a measure of treatment progress; that is, more psychopathic men simply displayed less change. In particular, men scoring high on the Affective facet and thus possessing significant callous-unemotional features demonstrated the least amount of change.

Psychopaths also present other treatment challenges (Wong, 2015; Wong, Gordon, Lewis, Gu, \& Olver, 2012). They can be verbally and emotionally abusive, threatening, and intimidating toward staff and patients. They may be disruptive in their treatment groups and hostile and resistant to feedback, leaving others on edge. By contrast, other psychopaths might be quite likable, interpersonally astute and adept at sizing up people and situations. Unfortunately, such skills are often used for negative or untoward purposes such 
as to manipulate staff for special privileges or favours, push boundaries, coerce patients for various ends, or to pit staff against one another (a phenomenon known as staff splitting). In the latter instance, some treatment staff may serve as a biased advocate for the patient, in contrast to other providers who have grown weary of the individual's conduct and may wish for them to be discharged.

Finally, when staff do not maintain clear lines of communication, enforce rules, maintain clear boundaries, or manage their emotional reactions to the men they treat (i.e., counter-transference), the patient, the broader program, and the staff suffer. These dynamics can engender various counter-transference reactions, whether it be angry and abusive retaliation, feeling helpless and preyed upon, or developing personal or sexualized feelings for the offender - all of which do not bode well for the patient's retention in treatment. While experiencing counter-transference is the rule rather than the exception when working with difficult clients, a clinician must manage emotional reactions towards patients so that the clinician can remain helpful, ethical, and effective as a therapist. A natural question to follow is to what extent psychopathic men may benefit when they are successfully retained in treatment?

\section{TREATMENT OF PSYCHOPATHY: A REVIEW OF THE EXISTING LITERATURE}

In 2002, Salekin published a meta-analysis of the psychopathy treatment literature. Featuring 42 studies traversing 60 years of therapeutic research, the body of work featured nearly a dozen psychotherapeutic interventions attempted with clientele identified as psychopathic. The designs ranged from large scale evaluations of programs featuring several hundred patients to single case studies. The largest portion of studies featured psychoanalytic interventions $(\mathrm{k}=17)$, followed by therapeutic communities $(\mathrm{k}=8)$, cognitive behavioural treatment (CBT) programs $(\mathrm{k}=5)$, eclectic, pharmacotherapy, and electroconvulsive shock therapy (ECT) ( $\mathrm{k}=2$ for each), and actional procedures, personal construct therapy, rational emotive therapy, psychodrama, and unspecified interventions ( $\mathrm{k}=1$ each). In addition, $\mathrm{k}=8$ of the studies featured a no treatment control condition. On average, Salekin (2002) found that approximately $62 \%$ of patients benefited from treatment, $60 \%$ when removing case studies. The highest success rates were often reported for studies of single interventions featuring a single case design; however, even when examining across larger collections of studies grouped by intervention, treatment effects were observed for psychoanalytic (59\% success rate) and CBT (62\% success rate). By contrast, little or no improvement beyond a no treatment control (20\% success rate) was found for ECT ( $22 \%$ success rate), therapeutic communities (TC) (25\% success rate), and the unspecified intervention (17\% success rate).

While on the surface this appears encouraging, there were a number of methodological limitations of the designs. First, many of these were single-case designs of a lone intervention and lacked replication. Further, the programs often featured antiquated interventions that predated the principles of effective correctional treatment (Andrews \& Bonta, 2010). The majority of studies did not employ the PCL-R or other validated operationalization to identify psychopathic offenders, often referring to looser collections of criteria (such as the Cleckley criteria) available at the time. Finally, most of the studies did not have an untreated control or comparison group, and few of them followed up their clients post-treatment or examined recidivism as an outcome variable. With regard to the lattermost point, the studies tended to examine a puzzling array of indicators of treatment success such as the clients being "less sociopathic", having greater empathy and anxiety, increased capacity for guilt, demonstrating improved relationships, decreased aggression and hostility, reduced institutional misconduct, or reductions in criminal charges and convictions. These considerations, notwithstanding, Salekin (2002) concluded "there is little scientific basis for the belief that psychopathy is an untreatable disorder" (p. 79).

In an updated synthesis, Salekin, Worley, and Grimes (2010) reviewed a number of psychopathy treatment studies published subsequent to their review, as well as revisiting the more methodologically sound investigations from the earlier Salekin (2002) review. Featuring $k=8$ treatment studies on adult samples and $k=5$ studies on child and youth samples, all investigations used a coherent operationalization of psychopathy (e.g., PCL-R), examined treatment outcome in terms of forensically relevant criteria, and employed a contemporary model of intervention such as CBT or variations on TC. Salekin et al. (2010) found that the treatment effects tended to be small and that child and adolescent populations generally derived greater benefit; however, not all programs were equally effective or evidence informed, and some published studies of reputable programs were overlooked (e.g., Looman, Abracen, Serin, \& Marquis, 2005), or earlier versions of updated studies were reviewed (e.g., Seto \& Barberee, 1999 in contrast to Barbaree, 2005, and Langton, Barbaree, Harkins, \& Peacock, 2006).

In the remainder of this article, I will examine some of the studies from Salekin et al. (2010), giving an update of works published since and a spotlight on those overlooked in the review. In doing so, I will review the characteristics and findings of both unsuccessful and encouraging programs, including providing an overview of a treatment model to guide intervention approaches with psychopathic offenders in correctional settings.

\section{UNSUCCESSFUL PROGRAMS}

\section{Controversial Findings from a Therapeutic Community (TC)}

A common thread among the unsuccessful programs identified earlier in Salekin (2002) and reinforced in Salekin et al. (2010), is that these often featured TCs. The TC is based on the premise that a milieu or environment that is therapeutic can be created which is conducive to positive behaviour change; however, how this is implemented varies dramatically and not all TCs are created equal. In a classic study of a TC operated through the Penetanguishine Mental Health Centre in Ontario, Rice, Harris, and Cormier (1992) conducted a retrospective archival investigation of a TC operated out of the institution during the 1960s and 70s, developed by psychiatrist Dr. Elliott Barker. Most of the patients were mentally ill offenders detained on a Lieutenant Governor's warrant, while some were remanded by the courts. Treatment was 
intensive, typically lasting 80 hours per week, in which the men would be locked in groups in small rooms, left to discuss their issues and to confront each other on their behaviour. There was little staff-patient contact, with the men being left essentially to run their own treatment. Hallucinogens and sedatives would be administered to lessen defenses or to augment disclosure, often at the direction of other patients. The men would be subjected to group pressures, nude encounter groups, or deprivation in various forms, with some providing narrative accounts afterward about the psychological toll of the program.

The Rice et al. (1992) study compared 176 men treated in the TC to 146 controls, all whom were rated on the PCL-R from file information, matched on age and offense history, and followed up an average 10 years post-release. Interestingly, a treatment effect was found for non-psychopathic men, of whom $39 \%$ of untreated men were convicted for a new violent offense, in contrast to $22 \%$ of treated nonpsychopathic men; however, $77 \%$ of the treated psychopaths were convicted for a new violent offense in contrast to $55 \%$ of untreated psychopaths! This was a statistically significant difference indicating an iatrogenic effect, that is, treatment making psychopathic offenders worse. Rice et al. (1992) concluded, "The results strongly suggest that the kind of therapeutic community described in this article is the wrong program for serious psychopathic offenders" (p. 408). Although this study served as a strong evaluation of a clearly inappropriate program, unfortunately its results would be frequently interpreted as proof positive that not only were psychopathic offenders untreatable, but that treatment makes them worse (see Harris \& Rice, 2006; Salekin, 2002; Salekin et al., 2010).

\section{Features of Unsuccessful Programs}

With this in mind, it is worth reviewing some of the features of unsuccessful programs. First, programs such as these clearly over-treated the men; even high-intensity correctional programs tend to be limited to 10-15 hours per week over the course of 8 or 9 months, totalling 450 to 500 hours of services (Olver \& Wong, 2013); such a total could be achieved in a matter of weeks with some TCs. The programs also did not match dosage or intensity to the men's risk level, nor did they do an intake of their risks and needs to guide service delivery. Further compounding matters, there was little or no staff oversight, supervision, contact, guidance, or prosocial role modelling. Such conditions are ripe for psychopaths to victimize vulnerable patients, as well as amounting to many missed opportunities for staff to provide the patients with skills training or development of new competencies.

It is also important to note that these programs often had unrealistic or inappropriate treatment targets (e.g., development of warmth, empathy, self-esteem, and insight) and emphasized the cultivation of skills that were not particularly risk relevant (e.g., demonstrating empathy in communication) or could even be misused, such as becoming more adept at manipulating others. While the men may have developed a greater understanding of themselves, they did little to improve upon the areas of concern that brought them in contact with the law to begin with (e.g., antisocial attitudes, employment/education skills deficits) or to develop functional pro-social behaviour skills to promote community reintegration. Finally, some of these programs employed strategies that were frankly harmful, violated human liberties, and were of dubious ethical nature. These circumstances are particularly concerning when considering that such programs typically provided services to vulnerable groups of men, who often presented with serious histories of violence and fragile mental health.

\section{ENCOURAGING PROGRAMS}

\section{Program Characteristics}

To characterize all TC programs as having the characteristics outlined in the previous section would be misleading, as some such programs are grounded in evidence-informed correctional treatment principles and have promise and potential. The Salekin (2002) and Salekin et al. (2010) reviews discussed previously further identified CBT-based programs as having a positive success rate in the treatment of psychopathic clients, and generally better outcomes relative to controls. Some features of encouraging programs are discussed here.

In their commentary on the psychopathy treatment literature, Simourd and Hoge (2000) aptly note, "the treatment of psychopaths has an interesting history, short on quality and long on lore ... close examination of the treatment studies of psychopaths shows that most treatment efforts have failed to attend to the principles of effective interventions" (p. 270). Simourd and Hoge (2000) are alluding to the risk, need, and responsivity principles (also known as RNR) of effective correctional intervention, adherence to which is common to encouraging programs. Briefly, the risk principle states that treatment intensity or dosage should be matched to the risk level of the offender, such that high-risk offenders receive a higher dosage of services, while low-risk offenders receive few or minimal services. The need principle asserts that dy namic risk factors, also known as criminogenic needs, which are linked to the origin and maintenance of antisocial behaviour and have the potential to change through treatment or other change agents (e.g., negative peers, antisocial attitudes, substance abuse, poor use of leisure, etc.), should be prioritized for treatment services. Finally, the responsivity principle states that treatment should employ cognitive behavioural methods of behaviour change (general responsivity), and that services should be adapted to the unique characteristics of correctional clientele that can impact response to services (e.g., motivation, learning style, cognitive ability, culture, personality).

Wong (2015; Wong \& Hare, 2005; Wong et al., 2012) has proposed a two-component model for the treatment of psychopathy involving applications of RNR: Component 1 is termed the Interpersonal Component and entails managing the Factor 1 characteristics of the syndrome as a responsivity issue, while Component 2 is termed the Criminogenic Component and involves treating the criminogenic needs associated with Factor 2, per the risk and need principles. The rationale behind this model has appeal and is predicated on the assumption that the primary objective in the treatment of psychopathic offenders is to reduce their risk for violence or other serious antisocial behaviour (e.g., sexual violence). First, cross-sectional research demonstrates that the personality and emotional features of psychopathy (Factor 1) 
tend to be stable across the lifespan, while the antisocial lifestyle features of Factor 2 tend to drop precipitously with advancing age, particularly after age 40 (Harpur \& Hare, 1994). Similar trends are seen with the age crime curve, as criminal behaviour starts to taper off as offenders reach middle age (Sampson \& Laub, 2003). Second, Factor 1 tends to be a less potent predictor of violence or other recidivism outcomes (Leistico et al., 2008; Yang, Wong, \& Coid, 2010) than Factor 2, and it is also less strongly correlated with measures of risk and criminogenic need than Factor 2 (Olver \& Wong, 2009).

It should come as little surprise that the character structure of psychopathy remains stable across the lifespan, and that trying to change the person's personality as the dominant focus of treatment is likely to be greeted with little success. Attempting to do so would be akin to an attempt to transform these individuals into warm, empathic, considerate beings who experience the normal range and intensities of human emotion. Not only are such attempts likely to fail, but there is little evidence that targeting the psychopath's personality in treatment is linked to reductions in violence and other forms of recidivism. By contrast, there is an abundance of evidence that making risk-relevant changes on criminogenic needs is associated with decreases in most recidivism outcomes (e.g., Olver, Lewis, \& Wong, 2013).

\section{Implementation of the Two-Component Model}

Managing Factor 1 as a responsivity issue (or set of responsivity issues) is not easy. The treatment interfering behaviours of psychopaths and other therapeutic challenges they bring, reviewed earlier in this article, are a precise illustration of how some of the interpersonal and affective features of the syndrome can play out. The key, Wong (2015) notes, is management and containment of these behaviours, and for service providers to make all reasonable efforts to retain these individuals in treatment. After all, jettisoning patients from treatment for displaying the very issues that got them there has a strange irony to it, in addition to removing any option for them to potentially benefit. Briefly, the model's approach would involve staff maintaining a united front, having clear and open lines of communication, and sustaining a supportive atmosphere conducive to frank collaboration and open consultation. Staff need to engage in self-care, monitor and manage their counter-transference reactions, and seek support. Staff training, including the maintenance and role modelling of good treatment boundaries, as well as routine documentation of all patient contacts and a commitment to treatment integrity, is key. Support from all levels of management, health, and security, is also critical; effective intervention and institutional security are not mutually exclusive but rather complement one other, as patients who receive quality services and are well managed are also less of a security threat.

In terms of the criminogenic prong of Component 2, this largely involves business as usual in the treatment of high-risk, high-needs offenders. Psychopathic offenders are often candidates for at least moderate, if not high-intensity, programs targeted toward their criminogenic needs. Likely this would entail a combination of group and individual services, and a mixture of specialized (e.g., substance abuse treatment, educational or vocational upgrading) and more comprehensive programs, such as a multi-modal violence reduction program or sex offender treatment program. Such programs would target multiple criminogenic needs that may vary depending on the program's emphasis. For instance, a violence reduction program may have anger management and aggression reduction as prominent components, while a sex offender program would have the management of sexually deviant interests and maladaptive sexual behaviour as treatment options. Such programs, by necessity, would include administration of a dynamic risk assessment tool (e.g., Violence Risk Scale (VRS), see Wong \& Gordon, 2006; Level of Services/Case Management Inventory (LS/CMI), see Andrews, Bonta, \& Wormith, 2004) to identify the individual's profile of criminogenic needs, to track and monitor treatment improvements (or deterioration) over treatment, and to assess the individual's readiness for change. The interventions would be primarily CBT in nature, arranged according to focused modules (e.g., anger management, relationships and intimacy skills, cognitive strategies), allowing for group process as well as opportunities for individual services. Treatment would naturally entail the development of new skills and strategies in replacement of former antisocial criminal modes of thinking and behaving.

\section{Canadian Content: A Review of Findings from Encouraging Programs}

As our knowledge of what potentially works with psychopathic offenders improves, along with the rigor of our methods to study it, the literature has continued to expand in promising directions. Here, I provide a brief review of recent findings with an emphasis on Canadian programs, building off the Salekin (2002; Salekin et al., 2010) reviews. The common thread among these programs is that they are all based out of the Correctional Service of Canada (CSC), thus featuring federal offenders (i.e., serving sentences of a minimum 2 years), and are grounded in the RNR principles. In each instance, psychopathy was assessed after the fact by way of file review, and under most circumstances, the programs would have been treating psychopathic offenders as part of their routine treatment practice without necessarily being aware of it.

The first collection of studies is based on evaluations of high-intensity treatment programs operated out of the RPC, a multi-level security CSC-based correctional treatment facility, located in Saskatoon, SK. Olver and Wong (2009) examined a sample of 156 adult male sex offenders who attended the Clearwater High Intensity Sex Offender Program, followed up an average 10 years post-release in the community. In addition to the PCL-R, the Violence Risk Scale-Sexual Offender version (VRS-SO; Wong, Olver, Nicholaichuk, \& Gordon, 2003), a sex offender risk assessment and treatment planning tool, was also rated on the sample from file information. A cut off score of 25 on the PCL-R was used to characterize psychopathy, which has been recommended for file-based ratings since archival ratings tend to underestimate the interpersonal and affective features of the syndrome (Wong, 1988). The researchers found that most of the psychopathic men who attempted treatment actually completed it (73\%), and that psychopathic treatment completers had a one-third reduction in rates of violent recidivism relative to psychopathic men who dropped out. After controlling for baseline risk 
and PCL-R score, positive treatment change (measured by the VRS-SO) was significantly associated with reductions in post-treatment sexual and violent recidivism. Even among psychopathic offenders, treatment change was significantly negatively correlated with violent recidivism $(r=-.40)$, such that psychopaths making more substantive changes had lower rates of new violent offenses. The change findings have since been replicated and extended to a larger cohort of 302 patients from the Clearwater Program (Sewall, 2015).

Olver et al. (2013; see also Lewis et al., 2013) subsequently examined a sample of 152 treated violent offenders from the RPC's ABC Program (referenced earlier), followed up an average of 5 years post-release in the community. The men were also rated on the VRS from file information to assess violence risk and treatment change. This was a particularly high-risk sample, with a mean PCL-R score of 26 and VRS score of 61 , the latter of which is about 1.5 standard deviations above Wong and Gordon's (2006) validation sample. Olver et al. (2013) found that VRS-measured treatment change was significantly associated with reductions in post-program violent recidivism after controlling for PCL-R score; the amount of risk reduction corresponded to an estimated $10 \%$ decrease in the hazard of a new violent offense for every one-point increase in change score, when holding PCL-R score constant. The results indicate risk-relevant treatment changes were meaningfully linked to reductions in violent recidivism in a high-risk psychopathic sample.

Wong et al. (2012) further compared 32 treated psychopathic offenders who had completed the ABC Program, to a comparison group of 32 untreated psychopathic men who were closely matched on a series of risk, criminal history, age, and other demographic and criminological predictor variables. The two groups did not differ substantively on a series of outcome criterion variables including rates of binary recidivism, number of new convictions, or time to reconviction; however, the treated psychopathic offenders had accumulated significantly less aggregate time for new offenses compared to the untreated psychopathic men. As sentence length has been established to be a good proxy for offense severity (Olver, Nicholaichuk, Gu, \& Wong, 2013), longer sentences entail more serious offenses; thus the reduction in aggregate sentence length (by nearly half) of treated psychopathic offenders is a persuasive indication of harm reduction for the treated men.

The next set of studies feature an iterative program of research that evaluated the Warkworth Sexual Behavior Clinic (WSBC), a moderate intensity sex offender program previously operated out of Warkworth (medium security) Institution in CSC Ontario Region. In the first of these studies, Seto and Barbaree (1999) examined the association of psychopathy and treatment behaviour to post-program recidivism in a sample of 224 treated sex offenders followed up 32 months post-release. Men scoring 15 or higher on the PCL-R who displayed good treatment behaviour paradoxically had higher rates of violent recidivism than similarly scoring men who displayed poor treatment behaviour. At the time this study was published, it created quite a stir as the findings were reminiscent of Rice et al.'s (1992) evaluation of the Penetanguishine TC, with the implications that even a seemingly sound treatment program could make psychopathic offenders worse. In a sequel to this study, Barbaree
(2005) extended the follow-up time of the sample to 5.2 years (62 months) and obtained more comprehensive recidivism data from the Canadian Police Information Centre (CPIC), the RCMP's national criminal record database. With the new outcome data and extended follow-up, Barbaree found that there were no differences in rates of violent recidivism between psychopathic men who displayed good (34\% recidivism) vs. poor $(30 \%$ recidivism), treatment behaviour. This quelled the controversy some, as the conclusion from the WSBC data shifted from the program potentially making psychopathic men worse, to one of the program simply not generating recidivism reductions for psychopathic sex offenders.

Most recently, Langton et al., (2006) expanded the WSBC sample to 418 treated sex offenders, obtaining comprehensive outcome data from CPIC, and following the sample up for 5 years post-release. In addition, the Langton study used a much higher cut-off to characterize psychopathy in this sample, a score of 25, as conventionally used for file-based ratings (Wong, 1988). (The use of a cut score of 15 in the two prior WSBC investigations would have generated more heterogeneous samples, of which only a portion would have been truly psychopathic.) In contrast to previous findings, Langton et al. (2006) found a significant psychopathy $X$ treatment behaviour interaction $(\mathrm{B}=1.41, p<.05)$, such that psychopathic men who displayed poor treatment behaviour had a significantly higher and faster rate of sexual recidivism over the follow-up period than psychopathic men who displayed good treatment behaviour. Specifically, there was about a twofold increase in the failure rates for sexual recidivism for the high psychopathy-poor treatment response group, compared to the other groups. The conclusions once again would seem to shift such that with methodological improvements, such as using a higher PCL-R cut score and comprehensive outcome data with extended follow-up, an evidence backed prisonbased sex offender treatment program generated recidivism reductions for the psychopathic men who performed well in it.

Finally, Looman et al. (2005) examined the association of PCL-R-measured psychopathy and treatment change to recidivism in a sample of 99 high-risk, high-need sex offenders, who attended the Regional Treatment Centre Sex Offender Treatment Program in Kingston, ON. The program was a 7-month high-intensity treatment service, modelled on the RNR principles, with many similarities to the RPC's Clearwater Program. Looman and colleagues examined two indicators of treatment change: 1) evaluations as to whether the men had made good vs. poor treatment progress, and 2) whether the men were evaluated as having lowered their risk level at the end of treatment. There was no association between treatment progress and recidivism among the psychopathic men; that is, high PCL-R scoring men (using a 25-point cut-off) who were judged as having made good treatment progress were no different than men judged as having made poor treatment progress. However, the 20 psychopathic men who were evaluated as having lowered their risk at the end of treatment had lower rates of violent recidivism $(30 \%)$ over the follow-up period than the 22 psychopathic men who were evaluated as not having lowered their risk (50\%). Although this represents an absolute $20 \%$ reduction in the rate of post-release violent recidivism, which is arguably quite substantial, a pairwise comparison of the 
magnitude of the difference between survival curves did not attain significance, likely owing to the small cell sizes and thus limited statistical power.

\section{CONCLUSION}

The treatment of psychopathic offenders remains a clinical matter that is often steeped in pessimism and controversy. In many respects, the field has come a long way since the early days of well-intentioned, but ultimately ineffective, programs, and the rise of more rigorous methodology, coupled with RNR-based treatment applications to psychopathic offenders, seems to have softened the stance of therapeutic pessimism to some degree. At this juncture, there is no evidence that appropriate treatment programs make psychopathic offenders worse, and there is some evidence to suggest that they may potentially benefit if retained in an evidence-informed treatment program. Wong's (2015) two-component model for the treatment of psychopathy provides a framework for managing and containing the treatment-interfering behaviours of psychopathic clientele, while maintaining treatment integrity to go about the critical task of effectively addressing core risks and needs to reduce recidivism and promote successful community reintegration. As the evidence accumulates, this gives further hope that growth in our knowledge, clinical practice, and evaluation of intervention efforts will improve our ability to help this challenging population.

\section{ACKNOWLEDGMENTS}

The author thanks his friends/colleagues for their valuable contributions to the collaborative works discussed in this article.

\section{CONFLICT OF INTEREST DISCLOSURES}

The author declares there are no conflicts of interest.

\section{AUTHOR AFFILIATIONS}

*Department of Psychology, University of Saskatchewan, Saskatoon, SK, Canada.

\section{REFERENCES}

Andrews, D. A. \& Bonta, J. (2010). The psychology of criminal conduct $\left(5^{\text {th }}\right.$ ed.). Abington, UK: Taylor \& Frances.

Andrews, D. A., Bonta, J., \& Wormith, J. S. (2004). Level of service/case management inventory (LS/CMI): An offender assessment system. User's guide. Toronto, ON: Multi-Health Systems.

Barbaree, H. E. (2005). Psychopathy, treatment behavior, and recidivism: An extended follow-up of Seto and Barbaree. Journal of Interpersonal Violence, 20(9), 1115-1131.

Beggs, S. M., \& Grace, R. C. (2008). Psychopathy, intelligence and recidivism in child molesters: Evidence of an interaction effect. Criminal Justice and Behavior, 35(6), 683-695.

Cleckely, H. (1941). The mask of sanity: An attempt to clarify some issue about the so-called psychopathic personality. St. Louis, MO: Mosby.

DeSorcy, D. R., Olver, M. E., \& Wormith, J. S. (2016). Working alliance and psychopathy: Linkages to treatment outcome in a sample of treated sexual offenders. Manuscript submitted for publication.

Forth, A. E., Kosson, D. S., \& Hare, R. D. (2003). Psychopathy Checklist: Youth Version (PCL:YV). Toronto, ON: Multi-Health Systems.

Guy, L. S., Edens, J. F., Anthony, C., \& Douglas, K. S. (2005). Does psychopathy predict institutional misconduct among adults? A meta-analytic investigation. Journal of Consulting and Clinical Psychology, 73(6) 1056-1064

Hare, R.D. (1991). The Hare Psychopathy Checklist-Revised. Toronto, ON: Multi-Health Systems

Hare, R. D. (1996). Psychopathy, a clinical construct whose time has come. Criminal Justice and Behavior, 23(1), 25-54

Hare, R. D. (2003). Manual for the Revised Psychopathy Checklist (2 ${ }^{\text {nd }}$ ed.) Toronto, ON: Multi-Health Systems.

Hare, R. D., \& Neumann, C. S. (2008). Psychopathy as a clinical and empirical construct. Annual Review of Clinical Psychology, 4, 217-246.

Hare, R. D., \& Neumann, C. S. (2010). The role of antisociality in the psychopathy construct: Comment on Skeem and Cooke (2010). Psychological Assessment, 22(2), 446-454.

Harpur, T. J., \& Hare, R. D. (1994). Assessment of psychopathy as a function of age. Journal of Abnormal Psychology, 103(4), 604-609.

Harris, G., \& Rice, M. (2006). Treatment of psychopathy: A review of empirical findings. In C. Patrick (Ed.), Handbook of psychopathy (pp. 555-572). New York, NY: Guilford.

Hart, S. D., Cox, D. N., \& Hare, R. D. (1995). The Hare Psychopathy Checklist: Screening Version (PCL: SV). Toronto, ON: Multi-Health Systems.

Hart, S. D., Kropp, P. R., \& Hare, R. D. (1988). Performance of psychopaths following conditional release from prison. Journal of Consulting and Clinical Psychology, 56(2), 227-232.

Hawes, S. W., Boccaccini, M. T., \& Murrie, D. C. (2013). Psychopathy and the combination of psychopathy and sexual deviance as predictors of sexual recidivism: Meta-analytic findings using the Psychopathy ChecklistRevised. Psychological Assessment, 25(1), 233-243.

Langton, C. M., Barbaree, H. E., Harkins, L., \& Peacock, E. J. (2006). Sex offenders' response to treatment and its association with recidivism as a function of psychopathy. Sexual Abuse: A Journal of Research and Treatment, 18(1), 99-120.

Leistico, A. R., Salekin, R. T., DeCoster, J., \& Rogers, R. (2008). A large-scale meta-analysis relating the Hare measures of psychopathy to antisocial conduct. Law and Human Behavior, 32(1), 28-45.

Lewis, K., Olver, M. E., \& Wong, S. C. P. (2013). The Violence Risk Scale: Predictive validity and linking treatment changes with recidivism in a sample of high-risk offenders with psychopathic traits. Assessment, 20, 150-164.

Looman, J. Abracen, J., Serin, R., \& Marquis, P. (2005). Psychopathy, treatment change, and recidivism in high-risk, high-need sexual offenders. Journal of Interpersonal Violence, 2015), 549-568.

Ogloff, J.D., Wong, S., \& Greenwood, M.A. (1990). Treating criminal psychopaths in a therapeutic community program. Behavioral Sciences and the Law, 8(2), 181-190

Olver, M. E., Lewis, K., \& Wong, S. C. P. (2013). Risk reduction treatment of high risk psychopathic offenders: The relationship of psychopathy and treatment change to violent recidivism. Personality Disorders: Theory, Research, and Treatment, 4(2), 160-167.

Olver, M. E., Nicholaichuk, T. P., Gu, D., \& Wong, S. C. P. (2013). Sex offender treatment outcome, actuarial risk, and the aging sex offender in Canadian corrections: A long-term follow-up. Sexual Abuse: A Journal of Research and Treatment, 25(4), 396-422.

Olver, M. E., Stockdale, K. C., \& Wormith, J. C. (2011). A meta-analysis of predictors of offender treatment attrition and its relationship to recidivism. Journal of Consulting and Clinical Psychology, 79(1), 6-21.

Olver, M. E., \& Wong, S. C. P. (2006). Psychopathy, sexual deviance, and recidivism among sex offenders. Sexual Abuse: A Journal of Research and Treatment, 18, 65-82

Olver, M. E., \& Wong, S. C. (2009). Therapeutic responses of psychopathic sexual offenders: treatment attrition, therapeutic change, and long-term recidivism. Journal of Consulting and Clinical Psychology, 77(2), 328. 
Olver, M. E., \& Wong, S. C. P. (2011). Predictors of sex offender treatment dropout: Psychopathy, sex offender risk, and responsivity implications. Psychology, Crime, and Law, 17/5), 457-471.

Olver, M. E., \& Wong, S. C. P. (2013). Treatment programs for high risk sexual offenders: Program and offender characteristics, attrition, treatment change, and recidivism. Aggression and Violent Behavior, 18(5), 579-591.

Olver, M. E., \& Wong, S. C. P. (2015). Short and long-term recidivism prediction of the PCL-R and the effects of age: A 24-year follow-up. Personality Disorders: Theory, Research, and Treatment, 6(1), 97-105.

Porter, S., Fairweather, D., Drugge, J., Hervé, H., Birt, A., \& Boer, D. P. (2000). Profiles of psychopathy in incarcerated sexual offenders. Criminal Justice and Behavior, 27(2), 216-233.

Rice, M. E., \& Harris, G. T., \& Cormier, C.A. (1992). An evaluation of a maximum security therapeutic community for psychopaths and other mentally disordered offenders. Law and Human Behavior, 16(4), 499-412.

Salekin, R. (2002). Psychopathy and therapeutic pessimism: Clinical lore or clinical reality? Clinical Psychology Review, 22(1), 79-112

Salekin, R., Worley, C. \& Grimes, R. (2010). Treatment of psychopathy: A review and brief introduction to the mental model approach for psychopathy. Behavioral Sciences and the Law, 28(2), 235-266.

Sampson, R. J., \& Laub, J. H. (2003). Life-course desisters? Trajectories of crime among delinquent boys followed to age 70. Criminology, 41(3), $555-592$.

Seto, M. C., \& Barbaree, H. E. (1999). Psychopathy, treatment behavior, and sex offender recidivism. Journal of Interpersonal Violence, 14(12), 1235-1248.

Sewall, L. A. (2015). The treatment of psychopathic sexual offenders: Exploring the influence of risk, change, subtype, and adaptation on recidivism. Unpublished doctoral dissertation, University of Saskatchewan, Saskatoon, SK, Canada.
Simourd, D.J., \& Hoge, R.D. (2000). Criminal psychopathy: A risk-and-need perspective. Criminal Justice and Behavior, 27(2), 256-272.

Suedfeld, P., \& Landon, P. B. (1978). Approaches to treatment. In R.D. Hare \& D. Schalling (Eds.), Psychopathic behavior: Approaches to research (pp. 347-376). Chichester: John Sright and Sons Ltd.

Wong, S. (1984). The criminal and institutional behaviors of psychopaths (User Report No. 1984-87). Ottawa, ON: Ministry of the Solicitor General of Canada.

Wong, S. (1988). Is Hare's Psychopathy Checklist reliable without the interview? Psychological Reports, 62(3), 931-934.

Wong, S. C. P. (2015). Treatment of violence prone individuals with psychopathic personality traits. In J. Livesley, G. Dimaggio \& J. Clarkin (Eds). Integrated treatment of personality disorder: A modular approach, (pp 345-376). New York, NY: Guildford.

Wong, S. C. P., \& Gordon A. (2006). The validity and reliability of the Violence Risk Scale: A treatment-friendly violence risk assessment tool. Psychology, Public Policy, and Law, 12(3), 279-309.

Wong, S. C. P., Gordon, A., Gu, D., Lewis, K., \& Olver, M. E. (2012). The effectiveness of violence reduction treatment for psychopathic offenders: Empirical evidence and a treatment model. International Journal of Forensic Mental Health, 11(4), 336-349.

Wong, S. \& Hare, R.D. (2005). Guidelines for a psychopathy treatment program. Toronto, ON: Multi-Health Systems.

Wong, S., Olver, M. E., Nicholaichuk, T. P., \& Gordon, A. (2003). The Violence Risk Scale: Sexual Offender version (VRS-SO). Saskatoon, SK: Regional Psychiatric Centre and University of Saskatchewan.

Yang, M., Wong, S. C. P. \& Coid, J. (2010). The efficacy of violence prediction: a meta-analytic comparison of nine risk assessment tools. Psychological Bulletin, 136(5), 740-767. 